\title{
Incidental Gallbladder Cancer on Cholecystectomy: Strategy for Re-resection of Presumed Benign Diseases from a Retrospective Multicenter Study by the Yokohama Clinical Oncology Group
}

\author{
RYUSEI MATSUYAMA ${ }^{1}$, KENICHI MATSUO $^{2}$, RYUTARO MORI $^{3}$, MITSUTAKA SUGITA ${ }^{4}$, \\ NAOTAKA YAMAGUCHI ${ }^{5}$, TORU KUBOTA ${ }^{6}$, KUNIO KAMEDA $^{7}$, YASUHISA MOCHIZUKI ${ }^{8}$, \\ RYO TAKAGAWA ${ }^{9}$, TOSHIAKI KADOKURA ${ }^{10}$, GORO MATSUDA $^{11}$, NORIYUKI KAMIYA ${ }^{12}$ and ITARU ENDO ${ }^{1}$ \\ ${ }^{1}$ Department of Gastroenterological Surgery, \\ Yokohama City University Graduate School of Medicine, Yokohama, Japan; \\ ${ }^{2}$ Department of Surgery, Fujisawa Municipal Hospital, Fujisawa, Japan; \\ ${ }^{3}$ Gastroenterological Center, Yokohama City University Medical Center, Yokohama, Japan; \\ ${ }^{4}$ Department of Surgery, Yokosuka Kyousai Hospital, Yokosuka, Japan; \\ ${ }^{5}$ Department of Surgery, Yokohama City Minato Red-Cross Hospital, Yokohama, Japan; \\ ${ }^{6}$ Department of Surgery, Saiseikai Yokohamashi Nanbu Hospital, Yokohama, Japan; \\ ${ }^{7}$ Department of Surgery, Yokosuka Municipal Hospital, Yokosuka, Japan; \\ ${ }^{8}$ Department of Surgery, Yokohama Municipal Citizens Hospital, Yokohama, Japan; \\ ${ }^{9}$ Department of Surgery, Saiseikai Wakakusa Hospital, Yokohama, Japan; \\ ${ }^{10}$ Department of Surgery, Yokohama Senin Hoken Hospital, Yokohama, Japan; \\ ${ }^{11}$ Department of Surgery, Yokohama Medical Center, Yokohama, Japan; \\ ${ }^{12}$ Department of Surgery, Ito Municipal Hospital, Ito, Japan
}

\begin{abstract}
Background/Aim: Current expert consensus recommends re-resection for incidental gallbladder cancer (IGBC) of pT1b-3. This study examined whether this consensus was reasonably applicable to patients with IGBC in one Japanese region. Patients and Methods: This was a multicenter, retrospective analysis of cholecystectomies for presumed benign diseases between January 2000 and December 2009. Results: IGBC was diagnosed in 70 (1.0\%) out of 6,775 patients undergoing cholecystectomy. Five-year disease-specific cumulative survival was $100 \%$ in 19 patients with pT1a, $80.0 \%$ in five with pT1b, $49.5 \%$ in 33 with pT2,
\end{abstract}

This article is freely accessible online.

Correspondence to: Ryusei Matsuyama, Department of Gastroenterological Surgery, Yokohama City University Graduate School of Medicine, 3-9 Fukuura, Kanazawa-ku, Yokohama, Kanagawa, 236-0004, Japan. Tel: +81 457872650, Fax: +81 457829161, e-mail: ryusei@terra.dti.ne.jp

Key Words: Gallbladder cancer, incidental, re-resection, bile spillage, outcome. and $23.1 \%$ in 13 with pT3. Re-resection was not performed for the 24 patients with pTla/lb disease, whereas 24 out of 46 patients with pT2/3 underwent re-resection. Regardless of re-resection, independent factors associated with a poor prognosis on multivariate analysis were grade 2 or poorer disease and bile spillage at prior cholecystectomy. In the 24 patients with pT2/3 re-resection, 11 patients without either of these two factors had significantly better 5-year diseasespecific cumulative survival than the 13 patients with one or two independent factors associated with a poor prognosis (72.7\% vs. 30.8\%, p=0.009). Conclusion: This Japanese regional study suggests that indication of re-resection for IGBC should not be determined by $p T$-factor alone and that much more attention should be paid to pathological and intraoperative findings at prior cholecystectomy.

Gallbladder cancer (GBC) is the most common biliary malignancy and the sixth most common gastrointestinal malignancy worldwide (1). Complete surgical removal is the only modality that can provide a chance of cure. However, the overall prognosis of patients with GBC has been dismal because the majority of cases have been judged to have unresectable disease at presentation (2) because it is very 
difficult to diagnose GBC preoperatively. As such, even today, GBC is often discovered incidentally on pathological examination following cholecystectomy for presumed benign diseases, despite recent advancements in diagnostic modalities (3-5). Furthermore, the number of patients undergoing cholecystectomy has been increasing since the advent of laparoscopic procedures, and, thus, cases of incidentally diagnosed GBC (IGBC) is considered to have further increased in number. Therefore, the clinical significance of IGBC should attract much more attention (3-8).

Current expert consensus (9) recommends re-resection for patients with IGBC with pT1b-3 disease because re-resection has been considered to provide a better chance of cure (5-9). However, a recent study demonstrated that the median survival time of patients with pT2/3 IGBC after extended cholecystectomy with adjuvant therapy was 16.1 months, while that after simple cholecystectomy with adjuvant therapy was 16.4 months (10). Although direct comparison of survival between these two procedures for pT2/3 IGBC was not performed in that study, these results suggested that adjuvant therapy without re-resection may be able to provide a treatment outcome comparable to that of re-resection for pT2/3 IGBC (10). In addition, a recent multicenter study comparing outcomes of surgery for pT1b GBC between simple cholecystectomy and extended resection found there to be no difference of treatment outcomes between these two procedures (11). As such, results of these studies may suggest that reresection is unnecessary for most patients with $\operatorname{IGBC}(10,11)$. In other words, the above-stated expert consensus may still include much room for debate.

This retrospective, multicenter study, which was conducted by the Yokohama Clinical Oncology Group (YCOG), examined whether the current expert consensus can be reasonably applied to patients with IGBC found in one Japanese region.

\section{Patients and Methods}

YCOG is a research group for investigating various concerns regarding surgery and oncology, and comprises the Department of Gastroenterological Surgery, Yokohama City University Graduate School of Medicine, and regional medical centers. The YCOG-1003 study group was organized to produce a retrospective registry of IGBC. Twelve centers of YCOG participants agreed on the contents of YCOG-1003 and were asked to identify all patients with IGBC to complete a multi-item questionnaire. Among patients who underwent cholecystectomy for preoperative diagnoses other than GBC between January 2000 and December 2009, cases of IGBC were extracted and retrospectively reviewed. A questionnaire sheet included the preoperative diagnosis for prior cholecystectomy, intraoperative findings of prior cholecystectomy, histopathological findings of prior cholecystectomy specimens, re-resection, use and details of additional treatment for patients in whom re-resection was not undertaken, interval between prior cholecystectomy and re-resection, procedure of re-resection, histopathological findings of re-resection specimens, the American Joint Committee on Cancer (AJCC) TNM classification
Table I. Patient demographic and tumor characteristics.

\begin{tabular}{llc}
\hline Variable & & Value \\
\hline Age, years & Median (range) & $69(37-90)$ \\
Gender, n (\%) & Male & $36(51.4 \%)$ \\
& Female & $34(48.6 \%)$ \\
Initial diagnosis, n (\%) & Cholecystolithiasis & $58(82.9 \%)$ \\
& GB polyps & $10(14.3 \%)$ \\
& Chronic cholecystitis & $5(7.1 \%)$ \\
& Adenomyomatosis & $1(1.4 \%)$ \\
& PBMJ & $1(1.4 \%)$ \\
Prior surgical procedure, & Open cholecystectomy & $30(42.9 \%)$ \\
$\mathrm{n}(\%)$ & Laparoscopic & $40(57.1 \%)$ \\
& cholecystectomy & \\
T-Stage, n (\%)a & $1 \mathrm{a}$ & $19(27.1 \%)$ \\
& $1 \mathrm{~b}$ & $5(7.1 \%)$ \\
& 2 & $33(47.1 \%)$ \\
Tumor differentiation, & 3 & $13(18.5 \%)$ \\
$\mathrm{n}(\%)^{\mathrm{a}}$ & G1 & $44(62.9 \%)$ \\
& G2 & $16(22.9 \%)$ \\
Re-resection, n (\%) & G3 & $9(12.9 \%)$ \\
& G4 & $1(1.4 \%)$ \\
& Absent & $46(65.8 \%)$ \\
& Present & $24(34.2 \%)$ \\
\hline
\end{tabular}

GB: Gallbladder, PBMJ: pancreaticobiliary maljunction. ${ }^{\mathrm{a} A m e r i c a n}$ Joint Committee on Cancer seventh edition (12).

staging (seventh edition) (12), short-term clinical course, and longterm outcomes. Furthermore, total number of cholecystectomies for preoperative diagnosis other than GBC performed during the study period in each institution was investigated and accumulated. This study was approved by the Ethical Committee Review Board of Yokohama City University School of Medicine (B100513018).

Statistical analysis. Continuous variables are presented as medians (range), and categorical variables are presented as frequencies. Categorical data were analyzed using the chi-squared test or Fisher's exact test. The Mann-Whitney $U$-test was used to compare continuous variables. Disease-free survival (DFS) was defined as the duration from the day of cholecystectomy to the day of diagnosis of relapsed disease or no evidence of relapsed disease. Disease-specific survival (DSS) was defined as the duration from the day of cholecystectomy to disease-specific death of the patient or latest follow-up. Cumulative survival rates were calculated by the Kaplan-Meier method and compared using the Peto-Prentice-Wilcoxon test. Factors found to be significant on univariate analysis or considered important for logical or biomedical grounds were subjected to multivariate analysis using a Cox proportional hazards model. A two-tailed $p$-value of less than 0.05 was considered significant. All statistical tests were performed using Microsoft Excel software (Microsoft, Redmond, WA, USA) and SPSS software ver. 22 for Windows (IBM Corporation, Armonk, NY, USA).

\section{Results}

Patient demographics and tumor characteristics. Between January 2000 and December 2009, 6,775 patients underwent cholecystectomy for presumed benign diseases at the 12 YCOG 


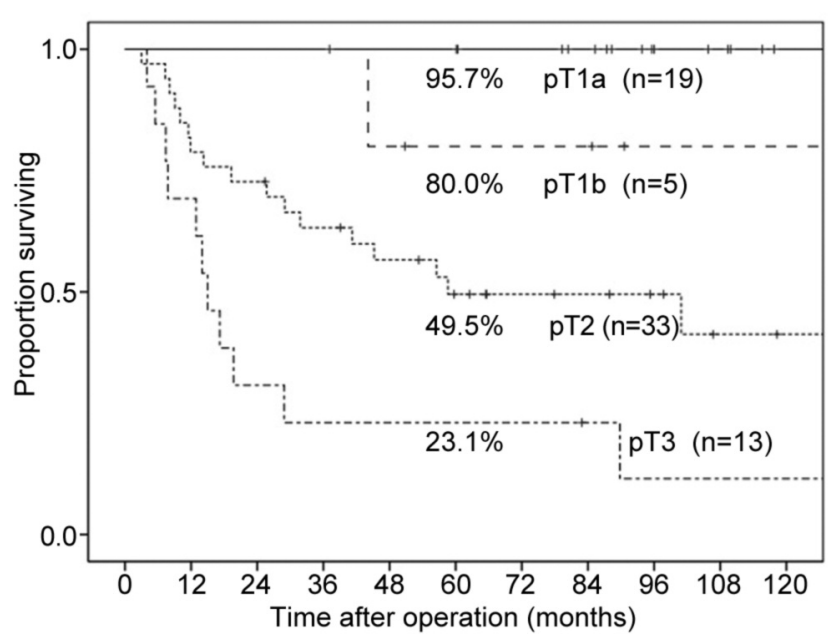

Figure 1. Kaplan-Meier survival curves of the entire study cohort stratified by the American Joint Committee on Cancer pT classification. These curves were clearly stratified by the American Joint Committee on Cancer pT classification.

institutions. Of these 6,775 patients, IGBC was diagnosed in $70(1.03 \%)$. Patient demographics and tumor characteristics are summarized in Table I. According to the AJCC staging system, cholecystectomy specimens showed pT1a tumor in 19 patients $(27.1 \%)$, pT1b in five $(7.1 \%)$, pT2 in $33(47.1 \%)$, and pT3 in $13(18.6 \%)$. None of the 24 patients with pT1a/1b underwent re-resection. Among the 51 patients with pT1b, pT2 or pT3 disease, for whom current expert consensus recommends reresection (9), 24 (47.1\%) underwent re-resection. No patients received treatments other than re-resection surgery for IGBC.

Prognostic significance of the AJCC pT classification. The observation period after prior cholecystectomy ranged from 4.0 to 194.4 months, with a median of 62.5 months. Regardless of whether re-resection was performed, survival outcomes after cholecystectomy were clearly stratified by the AJCC pT classification. The 5-year cumulative DSS was $100 \%$ in pT1a $(\mathrm{n}=19), 80.0 \%$ in pT1b $(\mathrm{n}=5), 49.5 \%$ in $\mathrm{pT} 2(\mathrm{n}=33)$, and $23.1 \%$ in pT3 $(n=13)$ cases (Figure 1). As stated above, no patients with $\mathrm{pT} 1 \mathrm{a} / 1 \mathrm{~b}$ disease underwent re-resection. One patient with $\mathrm{pT} 1 \mathrm{~b}$ disease who died of peritoneal recurrence 45 months after cholecystectomy showed bile spillage at cholecystectomy and grade 2 tumor differentiation on pathological examination. The remaining 23 patients with $\mathrm{pT} 1 \mathrm{a} / 1 \mathrm{~b}$ disease showed no bile spillage at cholecystectomy and none of the 23 patients died during the study period.

Prognostic analyses for patients with pT1b/T2/T3 disease. Cholecystectomy alone achieved a 5-year DSS of $100 \%$ in the 19 patients with pT1a disease. As the current expert consensus regards re-resection unnecessary for $\mathrm{pT} 1 \mathrm{a}$ disease, a prognostic
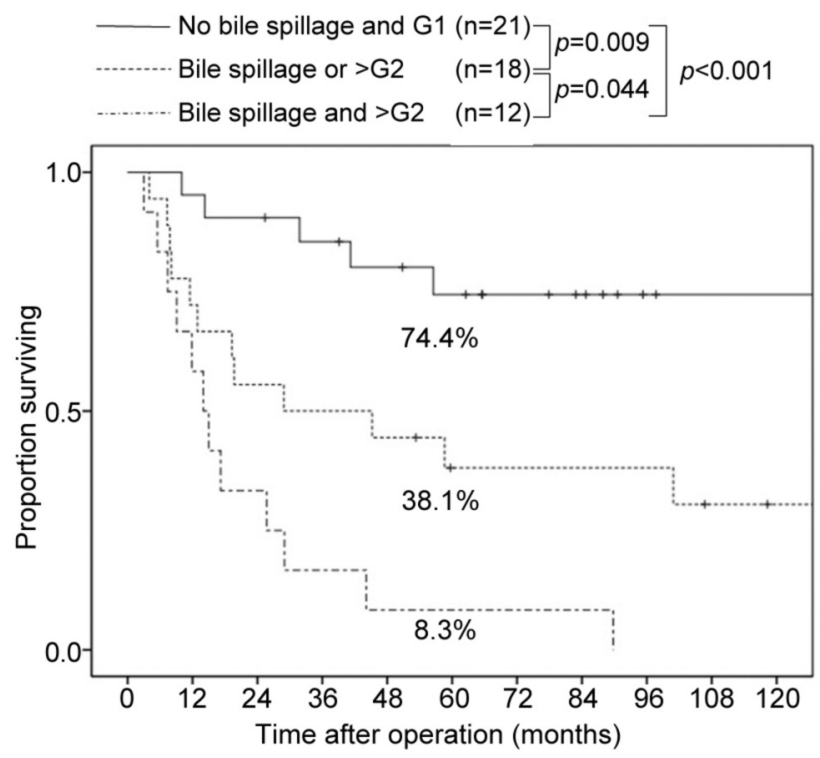

Figure 2. Survival outcomes of patients with pT1b, pT2 or pT3 incidental gallbladder cancer stratified by number of accompanying independent factors associated with a poor prognosis identified in the present study. Regardless of re-resection, survival outcomes of patients with pT2/3 disease are clearly stratified by the number of the following 2 independent factors associated with a poor prognosis: Grade (G) 2 or poorer disease and bile spillage at prior cholecystectomy. These rates decrease significantly according to the number of accompanying factors.

analysis was considered unnecessary for these patients. Thus, the 19 patients with pT1a disease were excluded from the subsequent prognostic analyses.

Considering only the 51 patients with pT1b, pT2 or pT3 disease, the prognostic significance of the following four variables was examined: Re-resection; AJCC pT classification; tumor differentiation; and occurrence of bile spillage at prior cholecystectomy. These four variables were evaluable at the time when the need for re-resection was decided. As shown in Table II, pT3 disease, poorer tumor differentiation (grade 2 or poorer), and bile spillage at prior cholecystectomy were significant factors associated with a poor prognosis on univariate analyses. Multivariate analysis using these four variables showed that poorer tumor differentiation (hazard ratio $=3.405 ; 95 \%$ confidence interval $=1.466-7.909$, and $p=0.004$ ) and bile spillage at prior cholecystectomy (hazard ratio $=2.768 ; 95 \%$ confidence intervaI $=1.288-5.951$; and $p=0.009$ ) were independent prognostic factors for survival of the 51 patients with pT1b- 3 disease. The 51 patients with pT1b3 disease were divided into three groups by the number of these independent factors they had: 21 Patients who had grade 1 disease and no bile spillage at prior cholecystectomy (no risk factor); 18 patients with either grade 2/poorer disease or bile spillage (one risk factor); and 12 patients with both grade $2 /$ poorer disease and bile spillage (two risk factors). The 
in vivo $35: 1217-1225(2021)$

Table II. Prognostic factors of 51 patients with $p T 1 b, p T 2$ or $p T 3$ incidental gallbladder cancer.

\begin{tabular}{|c|c|c|c|c|c|c|c|c|}
\hline \multirow[b]{2}{*}{ Variable } & & \multicolumn{4}{|c|}{ Univariate analysis } & \multicolumn{3}{|c|}{ Multivariate analysis } \\
\hline & & $\mathrm{n}$ & $\begin{array}{c}5 \text {-Year } \\
\text { survival (\%) }\end{array}$ & $\begin{array}{c}\text { Median } \\
\text { survival (Months) }\end{array}$ & $p$-Value & Hazard ratio & $\begin{array}{l}95 \% \text { Confidence } \\
\text { interval }\end{array}$ & $p$-Value \\
\hline \multirow[t]{2}{*}{ Re-resection } & No & 27 & 42.6 & 44.1 & 0.334 & & & \\
\hline & Yes & 24 & 49.7 & 56.5 & & & & \\
\hline \multirow[t]{2}{*}{ T-Stagea } & $1 \mathrm{~b}$ and 2 & 38 & 53.3 & 100.9 & & 1 (Ref) & & \\
\hline & 3 & 13 & 23.1 & 15.0 & 0.004 & 1.732 & $0.751-3.993$ & 0.198 \\
\hline \multirow[t]{2}{*}{ Tumor differentiationa } & Grade 1 & 26 & 67.9 & N.R. & & 1 (Ref) & & \\
\hline & $>$ Grade 2 & 25 & 23.3 & 19.3 & $<0.001$ & 3.405 & $1.466-7.909$ & 0.004 \\
\hline \multirow[t]{2}{*}{ Bile spillage } & No & 34 & 59.9 & 100.9 & & 1 (Ref) & & \\
\hline & Yes & 17 & 17.6 & 15.0 & $<0.001$ & 2.768 & $1.288-5.951$ & 0.009 \\
\hline
\end{tabular}

aAmerican Joint Committee on Cancer seventh edition (12).

survival curves of these groups were clearly stratified by the number of independent factors (Figure 2). The corresponding 5-year cumulative patient survival rates were $74.4 \%, 38.1 \%$, and $8.3 \%$, respectively. These rates were significantly better in those with one risk factor than in the other two groups ( $p=0.009$ and $p<0.001$, respectively) and significantly better in those with one risk factor than in those with two $(p=0.044)$.

Effects of re-resection. Because none of the five patients with pT1b disease underwent re-resection, these patients were excluded from the following analyses. Among the 46 patients with pT2/pT3 disease, the comparison of clinicopathological variables between the patients who underwent re-resection and those who did not is shown in Table III. Other than patient age, patient and tumor characteristics were similar between the two groups.

A comparison of cumulative survival between patients who underwent re-resection and those who did not showed that the 5 -year cumulative survival rate was not significantly different ( $49.7 \%$ in the former and $34.6 \%$ in the latter, $p=0.155$ ) (Figure $3 \mathrm{~A})$. Considering the two independent factors associated with a poor prognosis, that is grade 2 /poorer disease and bile spillage at prior cholecystectomy, however, the 5-year cumulative survival rate was significantly better in the 11 patients without either of the two independent factors associated with a poor prognosis who underwent re-resection than in the remaining 35 patients $(72.7 \% v s .32 .6 \%, p=0.007)$ (Figure 3B). Furthermore, a comparison of the 11 patients without independent factors and the 13 with one or two independent factors, who all underwent re-resection, showed that the 5-year cumulative survival rate was significantly better in the first group than those in the latter $(72.7 \%$ vs. 30.8\%, $p=0.007)$ (Figure 3C).

Unlike a recent report in which the interval between initial cholecystectomy and re-resection was significantly associated with outcomes of re-resection, there was no correlation between outcomes of re-resection and the interval (data not shown) (13). Furthermore, a recently introduced pathology-based preoperative risk score for re-resection of IGBC did not successfully stratify the survival outcomes of re-resection in the present study cohort (data not shown) (14).

Implications of grade 2/poorer disease and bile spillage at prior cholecystectomy. Based on the above analyses, grade 2/poorer disease and bile spillage at prior cholecystectomy were noted to have significant negative impacts on survival outcomes of patients with pT2/3 IGBC, regardless of whether re-resection was performed. To clarify the effects of these two factors on postoperative survival outcomes after re-resection, DFS and recurrence patterns were compared in the 24 patients who underwent re-resection between those with grade 1 disease and those with grade 2/poorer disease, and between patients with and without bile spillage at prior cholecystectomy.

With regard to tumor differentiation, the 5-year DFS rate and the median DFS were significantly lower in patients with grade $2 /$ poorer disease $(n=10)$ than in those with grade 1 disease $(\mathrm{n}=14)(13.1 \%$ vs. $57.1 \%$; and 12.0 months in those with grade $2 /$ poorer group $v s$. not reached, $p=0.031$ ). However, the site of recurrence did not differ among the groups (Table IV).

Regarding bile spillage at prior cholecystectomy, the 5-year DFS rate and median DFS were significantly lower in patients with bile spillage $(n=7)$ than in those without $(n=17)(5$-year DFS rate: $14.3 \%$ vs. $52.3 \%$; median DFS: 11.5 months vs. not reached, $p=0.048$ ) (Table IV). Unlike tumor differentiation, the recurrence pattern was significantly different between patients with and without bile spillage at prior cholecystectomy. Peritoneal recurrence was significantly more common in patients with bile spillage $(6 / 6,100 \%)$ than in those without $(2 / 8,25 \%)(p=0.023)$ (Table IV).

\section{Discussion}

The present study demonstrated that IGBC was observed in $1 \%$ of patients undergoing cholecystectomy for preoperative 
Table III. Comparison of clinicopathological variables of 46 patients with pT2/pT3 incidental gallbladder cancer between patients who underwent re-resection and those who did not.

\begin{tabular}{|c|c|c|c|c|}
\hline Variable & & $\begin{array}{l}\text { Re-resection } \\
\quad(\mathrm{n}=24)\end{array}$ & $\begin{array}{l}\text { No re-resection } \\
\qquad(\mathrm{n}=22)\end{array}$ & $p$-Value \\
\hline Age, years & Mean \pm SD & $66.3 \pm 6.7$ & $74.7 \pm 8.7$ & $<0.001$ \\
\hline \multirow[t]{2}{*}{ Gender, n (\%) } & Male & $13(54.2)$ & $12(54.5)$ & 0.800 \\
\hline & Female & $11(45.8)$ & $10(45.5)$ & \\
\hline \multirow[t]{5}{*}{ Initial diagnosis, $\mathrm{n}(\%)^{\mathrm{a}}$} & Cholecystolithiasis & $22(50.0)$ & $20(90.9)$ & 0.649 \\
\hline & GB polyps & $2(8.3)$ & $1(4.5)$ & \\
\hline & Chronic cholecystitis & $4(16.7)$ & $1(4.5)$ & \\
\hline & Adenomyomatosis & $0(0.0)$ & $1(4.5)$ & \\
\hline & PBMJ & $0(0.0)$ & $0(0.0)$ & \\
\hline \multirow[t]{2}{*}{ Prior cholecystectomy, n (\%) } & Open & $11(45.8)$ & $12(54.5)$ & 0.800 \\
\hline & Laparoscopic & $13(54.2)$ & $10(45.5)$ & \\
\hline \multirow[t]{2}{*}{ pT stage, $\mathrm{n}(\%)^{\mathrm{b}}$} & 2 & $15(62.5)$ & $18(81.8)$ & 0.196 \\
\hline & 3 & $9(37.5)$ & $4(18.2)$ & \\
\hline \multirow[t]{4}{*}{ Tumor differentiation, $\mathrm{n}(\%)^{\mathrm{b}}$} & Grade 1 & $14(58.3)$ & $10(45.5)$ & 0.825 \\
\hline & Grade 2 & $5(20.8)$ & $9(40.9)$ & \\
\hline & Grade 3 & $5(20.8)$ & $2(9.1)$ & \\
\hline & Grade 4 & $0(0.0)$ & $1(4.5)$ & \\
\hline \multirow[t]{2}{*}{ Bile spillage in prior operation, $\mathrm{n}(\%)$} & No & $17(70.8)$ & $13(59.1)$ & 0.403 \\
\hline & Yes & $7(29.2)$ & $9(40.9)$ & \\
\hline Time to re-resection & Median (range) & $30(14-84)$ & & \\
\hline \multirow[t]{2}{*}{ Surgical re-resection, n (\%) } & Gall bladder bed & $14(58.3)$ & & \\
\hline & Segment $4 \mathrm{~b} / 5$ & $10(41.6)$ & & \\
\hline \multirow[t]{2}{*}{ Bile duct resection, n (\%) } & Yes & $11(45.8)$ & & \\
\hline & No & $13(54.1)$ & & \\
\hline \multirow[t]{2}{*}{ Cancer remnant in re-resected specimen, $\mathrm{n}(\%)$} & No & $21(87.5 \%)$ & & \\
\hline & Yes & $3(12.5 \%)$ & & \\
\hline \multirow[t]{2}{*}{ Lymph node metastasis, $\mathrm{n}(\%)$} & No & $17(70.8 \%)$ & & \\
\hline & Yes & $7(29.1 \%)$ & & \\
\hline
\end{tabular}

PBMJ: Pancreatico biliary maljunction. a Data overlap. ${ }^{b}$ American Joint Committee on Cancer seventh edition (12).

diagnoses other than GBC, that almost all patients with AJCC pT1 disease survived more than 5 years without re-resection, and that the effect of re-resection was limited in patients with pT2/3 disease who did not have the two independent factors associated with a poor prognosis: grade 2 or poorer disease and bile spillage at prior cholecystectomy.

Geographic variation in the incidence of GBC is well known. The $1 \%$ incidence of IGBC which was confirmed by the present study was considered reasonable compared to previous studies (15-18).

In the basic concept, re-resection is considered to have the following two purposes: Elimination of residual disease, and accurate understanding of the extent of disease. For the former, resection of adjunct organs such as liver parenchyma or common bile duct, in which the disease is likely to remain, is considered necessary. Lymphadenectomy, which is usually included in the re-resection procedure, may be effective for both purposes. However, the prognosis of lymph node metastasis-positive GBC is reportedly dismal even when $\mathrm{R} 0$ resection is achieved $(2,19$, 20). Furthermore, it has been reported that the number of metastatic lymph nodes or the number of dissected lymph nodes, regardless of whether metastatic disease is proven in dissected lymph nodes, is significantly correlated with survival outcomes of surgery for $\operatorname{GBC}(20,21)$. Thus, lymphadenectomy should be considered necessary for accurate staging of the disease rather than for the elimination of residual disease.

Current expert consensus and the National Comprehensive Cancer Network (https://www.nccn.org/professionals/ physician_gls/default.aspx) recommended that patients with nonmetastatic pT1b, pT2, or pT3 stage disease undergo extended/radical cholecystectomy with en bloc liver resection ( 9 , 21-26). If this recommendation had been followed, 51 out of 70 patients with IGBC in the present study who had pT1b, pT2, or pT3 disease would have had to have undergone re-resection, although only 24 out of the 51 patients actually underwent reresection. With regard to $\mathrm{pT} 1 \mathrm{~b} \mathrm{GBC}$, the present study included only five patients with pT1b, none of whom underwent reresection. Thus, it was not possible to obtain conclusive findings regarding re-resection for $\mathrm{pT} 1 \mathrm{~b}$ IGBC from the results of the present study. However, all of the four patients with pT1b disease who did not exhibit bile spillage at cholecystectomy survived throughout the study period without re-resection. Furthermore, 

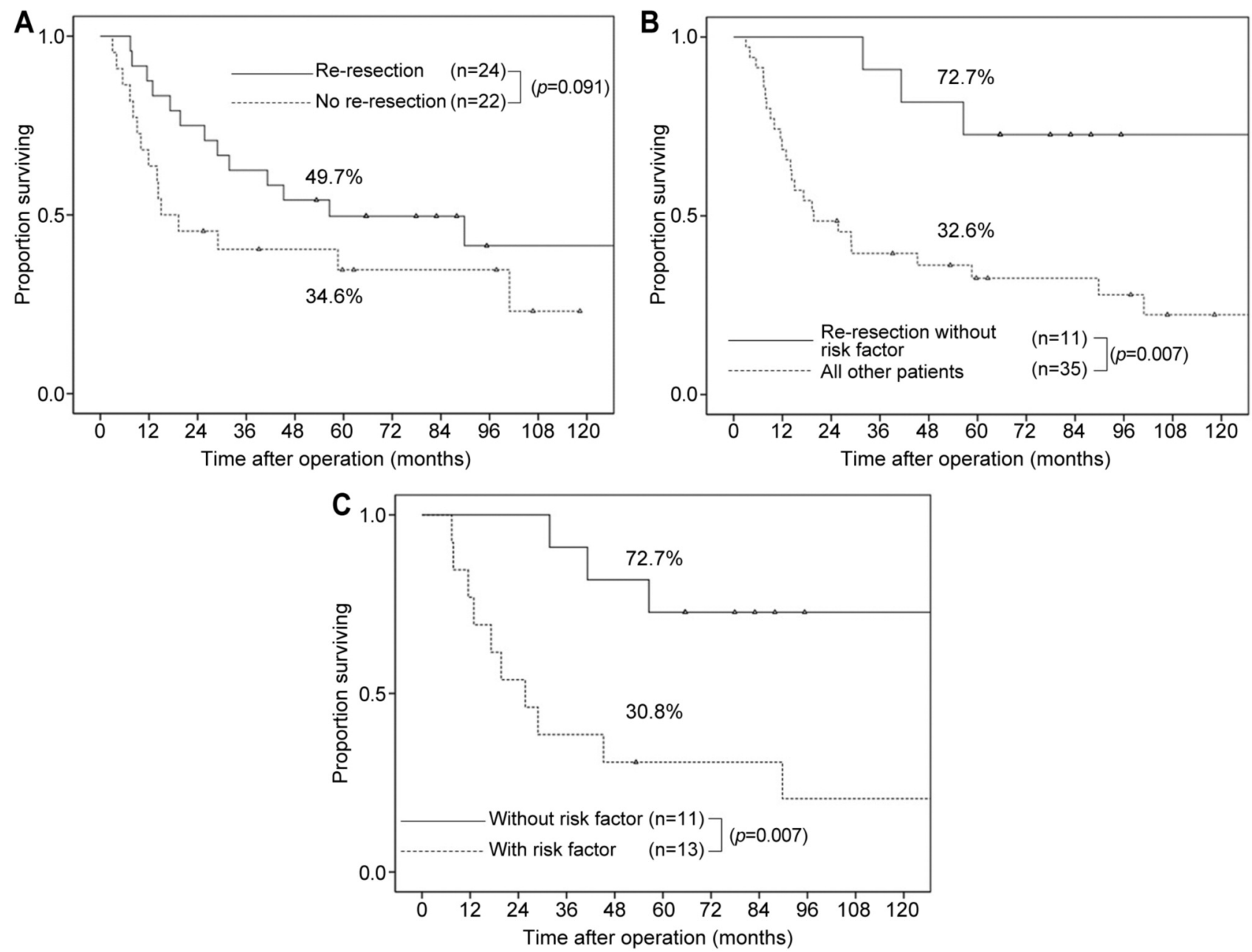

Figure 3. Effect of re-resection for pT2/3 incidental gallbladder cancer on survival outcomes. A: Comparison between those who underwent reresection and those who did not. The 5-year disease-specific survival rates were not significantly different ( $p=0.155)$. B: Comparison according to the presence of independent factors associated with a poor prognosis, namely grade 2 (G2) or poorer disease, or bile spillage at prior cholecystectomy. Survival of patients without any risk factor was significantly better ( $p=0.007)$. C: Comparison of patients who underwent reresection between those without any risk factor associated with a poor prognosis and those with one or two factors. The 5-year disease-specific survival rate was significantly better in those who had neither of the two independent factors associated with a poor prognosis ( $p=0.007$ ).

several Japanese institutions reported that survival outcomes of patients with pT1b GBC after cholecystectomy were satisfactory, with 5-year DSS of more than 90\% regardless of re-resection (2224). In addition, a very recent international multicenter study by Kim et al. comparing outcomes of surgery for pT1b GBC between simple cholecystectomy and extended resection showed that 5-year DSS of more than $90 \%$ was similar for these two procedures (11), suggesting that pT1b IGBC does not necessitate re-resection. In contrast, some reports from Western countries showed that the prognosis of pT1b was disappointing, with 5-year DSS of $50-60 \%(5,25,26)$ and upheld the necessity of reresection. Although it cannot be denied that the GBC that develops in Western populations may have a more biologically aggressive nature than that which develops in Asian patients, the report of Kim et al. included a considerable US population (11). Therefore, these discrepant surgical outcomes of pT1b GBC among reports appear to have resulted from interobserver variability in sampling methods of gallbladder specimen for presumed benign diseases rather than a difference in biological aggressiveness $(27,28)$. Hence, based on the above-stated Japanese reports (20-22) and the international multicenter study suggesting no need for re-resection for $\mathrm{pT} 1 \mathrm{~b}$ IGBC, we consider that re-resection is unnecessary for pT1b disease, at least in Japan.

Regarding pT2/3 disease, the results of the present study may sound a warning against the current expert consensus (9) because the survival benefit of re-resection was not proven. In other words, regardless of re-resection, survival outcomes of patients with pT2/3 were clearly stratified by the number of 
Table IV. Comparisons of disease-free survival and the site of recurrence after re-resection between patients according to the prognostic factors tumor grade and bile spillage at prior cholecystectomy.

\begin{tabular}{|c|c|c|c|c|c|c|c|}
\hline & & \multicolumn{3}{|c|}{ Grade } & \multicolumn{3}{|c|}{ Bile spillage } \\
\hline & & $>2(n=10)$ & $1(\mathrm{n}=14)$ & $p$-Value & Yes $(n=7)$ & No $(n=17)$ & $p$-Value \\
\hline Disease-free survival, $\%$ & 5-Year & 13.1 & 57.1 & 0.031 & 14.3 & 52.3 & 0.048 \\
\hline Time to relapse, months & Median (range) & $12.0(4.8-18.1)$ & N.R. & - & $11.5(0.4-22.5)$ & N.R. & - \\
\hline Recurrence, n (\%) & Yes & $8(80.0 \%)$ & $6(42.8 \%)$ & 0.161 & $6(85.7 \%)$ & $8(47.0 \%)$ & 0.196 \\
\hline \multirow[t]{5}{*}{ Recurrence site, n (\%) } & Local & $2(25.0 \%)$ & $0(0 \%)$ & 0.581 & $1(16.6 \%)$ & $1(12.5 \%)$ & 0.581 \\
\hline & Lymph node & $5(62.5 \%)$ & $2(33.3 \%)$ & 0.589 & $2(33.3 \%)$ & $5(62.5 \%)$ & 0.589 \\
\hline & Lung & $0(0 \%)$ & $2(33.3 \%)$ & 0.321 & $0(0 \%)$ & $2(25.0 \%)$ & 0.581 \\
\hline & Liver & $0(0 \%)$ & $1(16.6 \%)$ & 0.880 & $0(0 \%)$ & $1(12.5 \%)$ & 0.880 \\
\hline & Peritoneum & $4(50.0 \%)$ & $3(50.0 \%)$ & 0.589 & $6(100 \%)$ & $2(25.0 \%)$ & 0.023 \\
\hline
\end{tabular}

accompanying independent prognostic factors identified in the present study, namely tumor histological differentiation and bile spillage at prior cholecystectomy. Even with re-resection, eight out of 10 patients who underwent re-resection for grade 2 or poorer pT2/3 disease developed recurrence, and the median DFS for these 10 patients was only 12 months. Similarly, six out of seven patients with a history of bile spillage at prior cholecystectomy who underwent re-resection for pT2/3 IGBC developed peritoneal recurrence, and the median DFS of these seven patients was less than 12 months. Grade 2 or poorer disease was not significantly associated with any site of recurrence, whereas bile spillage was significantly associated with peritoneal recurrence after re-resection. Therefore grade 2 or poorer disease is likely to disseminate systemically due to its aggressive biological nature, and cancer cells may be scattered into the peritoneal cavity through bile spillage. As a result, micro-residual disease, which cannot be eliminated by re-resection, was considered to have arisen. In the present study, an obvious survival benefit of re-resection was obtained only in patients without these two independent risk factors. Both these factors can be evaluated at the time the decision of whether to proceed with re-resection is made. Recently, the significance of adjuvant therapy for GBC was reported (10); simple cholecystectomy with adjuvant therapy was shown to provide significantly better survival outcomes than extended resection alone, and a benefit of re-resection for pT2/3 IGBC was not shown (10). Therefore, systemic treatment, rather than re-resection, may have a greater impact for patients with factors associated with a poor prognosis. Hence, adjuvant therapy without re-resection for pT2/3 IGBC may be a choice of treatment in selected patients with either of the independent risk factors. Regarding bile spillage at cholecystectomy, Clemente et al. reported that treatment outcomes of IGBC after laparoscopic cholecystectomy for patients with acute cholecystitis were significantly worse than patients without cholecystitis (29), probably because of bile spillage related to intraoperative gallbladder emptying. As suggested in the current Japanese treatment guideline for acute cholecystitis (30), when bile spillage seems likely to occur, more detailed preoperative diagnostic imaging modalities may be necessary to detect GBC. Furthermore, careful selection of the operative procedure (open or laparoscopic) and meticulous intraoperative procedures are required for preventing intraoperative bile spillage. Although this may be an exaggeration, it may be stated that IGBC should always be kept in mind at cholecystectomy even if the preoperative diagnosis does not indicate it.

There were several drawbacks in the present study. Firstly, the sample size was very small despite it being a multiinstitutional study. At the same time, probable variations in management strategy existed due to the multicenter design. Despite these drawbacks, however, the results of the present study were quite convincing and worth taking into consideration when deciding treatment strategies for future patients because the survival outcomes of patients with IGBC in the present study were clearly stratified.

In conclusion, IGBC was observed in 70 out of 6,775 patients undergoing cholecystectomy for preoperative diagnoses other than GBC. Patients with pT1a had 5-year DSS of $100 \%$ without re-resection. Furthermore, an obvious survival benefit of re-resection was not found in patients with pT1b, pT2, or pT3 disease in univariate and multivariate analyses. The survival benefit of re-resection was obtained only in patients without either of two independent factors associated with a poor prognosis identified in the present study: Grade 2/poorer disease and bile spillage at prior cholecystectomy. These results suggest that indication for re-resection should not be determined by pT-factor alone in Japanese patients with IGBC and that much more attention should be paid to pathological findings as well as intraoperative findings at prior cholecystectomy.

\section{Conflicts of Interest}

The Authors declare no conflicts of interest for this article. 


\section{Authors' Contributions}

Conception and design of work: RM, IE. Acquisition of data: RM, KM, RM, MS, NY, TK, KK, YM, RT, TK, GM, NK. Data analysis and interpretation: All Authors have participated in critical revision of the manuscript for important intellectual content. Wrote the initial draft of the manuscript: RM. All Authors finally approved of the version to be published and agreed to be accountable for all aspects of the work in ensuring that questions related to the accuracy or integrity of any part of the work are appropriately investigated and resolved. All Authors have read and approved the manuscript.

\section{References}

1 Hundal R and Shaffer EA: Gallbladder cancer: Epidemiology and outcome. Clin Epidemiol 6: 99-109, 2014. PMID: 24634588. DOI: $10.2147 /$ clep.S37357

2 Miyakawa S, Ishihara S, Horiguchi A, Takada T, Miyazaki M and Nagakawa T: Biliary tract cancer treatment: 5,584 Results from the biliary tract cancer statistics registry from 1998 to 2004 in Japan. J Hepatobiliary Pancreat Surg 16(1): 1-7, 2009. PMID: 19110652. DOI: 10.1007/s00534-008-0015-0

3 Box JC and Edge SB: Laparoscopic cholecystectomy and unsuspected gallbladder carcinoma. Semin Surg Oncol 16(4): 327-331, 1999. PMID: 10332779. DOI: 10.1002/(sici)10982388(199906)16:4<327:aid-ssu8>3.0.co;2-v

4 Pawlik TM, Gleisner AL, Vigano L, Kooby DA, Bauer TW, Frilling A, Adams RB, Staley CA, Trindade EN, Schulick RD, Choti MA and Capussotti L: Incidence of finding residual disease for incidental gallbladder carcinoma: Implications for re-resection. J Gastrointest Surg 11(11): 1478-1486; discussion 14861477, 2007. PMID: 17846848. DOI: 10.1007/s11605-007-0309-6

5 Goetze TO and Paolucci V: Adequate extent in radical re-resection of incidental gallbladder carcinoma: Analysis of the German registry. Surg Endosc 24(9): 2156-2164, 2010. PMID: 20177938. DOI: $10.1007 / \mathrm{s} 00464-010-0914-4$

6 Fuks D, Regimbeau JM, Le Treut YP, Bachellier P, Raventos A, Pruvot FR, Chiche L and Farges O: Incidental gallbladder cancer by the AFC-GBC-2009 Study Group. World J Surg 35(8): 18871897, 2011. PMID: 21547420. DOI: 10.1007/s00268-011-1134-3

7 Goetze TO and Paolucci V: Benefits of reoperation of T2 and more advanced incidental gallbladder carcinoma: Analysis of the German registry. Ann Surg 247(1): 104-108, 2008. PMID: 18156929. DOI: 10.1097/SLA.0b013e318154bf5d

8 Shirai Y, Yoshida K, Tsukada K and Muto T: Inapparent carcinoma of the gallbladder. An appraisal of a radical second operation after simple cholecystectomy. Ann Surg 215(4): 326-331, 1992. PMID: 1558412. DOI: 10.1097/00000658-199204000-00004

9 Aloia TA, Járufe N, Javle M, Maithel SK, Roa JC, Adsay V, Coimbra FJ and Jarnagin WR: Gallbladder cancer: Expert consensus statement. HPB 17(8): 681-690, 2015. PMID: 26172135. DOI: $10.1111 / \mathrm{hpb} .12444$

10 Kasumova GG, Tabatabaie O, Najarian RM, Callery MP, Ng SC, Bullock AJ, Fisher RA and Tseng JF: Surgical management of gallbladder cancer: Simple versus extended cholecystectomy and the role of adjuvant therapy. Ann Surg 266(4): 625-631, 2017. PMID: 28692469. DOI: 10.1097/sla.0000000000002385

11 Kim HS, Park JW, Kim H, Han Y, Kwon W, Kim SW, Hwang YJ, Kim SG, Kwon HJ, Vinuela E, Járufe N, Roa JC, Han IW, Heo JS, Choi SH, Choi DW, Ahn KS, Kang KJ, Lee W, Jeong CY, Hong SC,
Troncoso A, Losada H, Han SS, Park SJ, Yanagimoto H, Endo I, Kubota K, Wakai T, Ajiki T, Adsay NV and Jang JY: Optimal surgical treatment in patients with $\mathrm{t} 1 \mathrm{~b}$ gallbladder cancer: An international multicenter study. J Hepatobiliary Pancreat Sci 25(12): 533543, 2018. PMID: 30562839. DOI: 10.1002/jhbp.593

12 Sabin LH GM and Wittekind C: TNM Classification of Malignant Tumors. Seventh Edition. Wiley-Blackwell: New York, 2010.

13 Ethun CG, Postlewait LM, Le N, Pawlik TM, Buettner S, Poultsides G, Tran T, Idrees K, Isom CA, Fields RC, Jin LX, Weber SM, Salem A, Martin RC, Scoggins C, Shen P, Mogal HD, Schmidt C, Beal E, Hatzaras I, Shenoy R, Kooby DA and Maithel SK: Association of optimal time interval to re-resection for incidental gallbladder cancer with overall survival: A multi-institution analysis from the us extrahepatic biliary malignancy consortium. JAMA Surg 152(2): 143-149, 2017. PMID: 27784058. DOI: 10.1001/jamasurg.2016.3642

14 Ethun CG, Postlewait LM, Le N, Pawlik TM, Buettner S, Poultsides G, Tran T, Idrees K, Isom CA, Fields RC, Jin LX, Weber SM, Salem A, Martin RC, Scoggins C, Shen P, Mogal HD, Schmidt C, Beal E, Hatzaras I, Shenoy R, Merchant N, Cardona $\mathrm{K}$ and Maithel SK: A novel pathology-based preoperative risk score to predict locoregional residual and distant disease and survival for incidental gallbladder cancer: A 10-institution study from the U.S. Extrahepatic Biliary Malignancy Consortium. Ann Surg Oncol 24(5): 1343-1350, 2017. PMID: 27812827. DOI: 10.1245/ s10434-016-5637-x

15 Are C, Ahmad H, Ravipati A, Croo D, Clarey D, Smith L, Price RR, Butte JM, Gupta S, Chaturvedi A and Chowdhury S: Global epidemiological trends and variations in the burden of gallbladder cancer. J Surg Oncol 115(5): 580-590, 2017. PMID: 28138977. DOI: $10.1002 /$ jso. 24546

16 Manfredi S, Benhamiche AM, Isambert N, Prost P, Jouve JL and Faivre J: Trends in incidence and management of gallbladder carcinoma: A population-based study in France. Cancer 89(4): 757762, 2000. PMID: 10951337. DOI: 10.1002/10970142(20000815)89:4<757:aid-cncr6>3.0.co;2-h

17 Akyürek N, Irkörücü O, Salman B, Erdem O, Sare M and Tatlicioğlu E: Unexpected gallbladder cancer during laparoscopic cholecystectomy. J Hepatobiliary Pancreat Surg 11(5): 357-361, 2004. PMID: 15549438:. DOI: 10.1007/s00534-004-0910-y

18 Mori T, Souda S, Hashimoto J, Yoshikawa Y and Ohshima M: Unsuspected gallbladder cancer diagnosed by laparoscopic cholecystectomy: A clinicopathological study. Surg Today 27(8): 710713, 1997. PMID: 9306584. DOI: 10.1007/bf02384982

19 Araida T, Higuchi R, Hamano M, Kodera Y, Takeshita N, Ota T, Yoshikawa T, Yamamoto M and Takasaki K: Hepatic resection in 485 R0 pT2 and pT3 cases of advanced carcinoma of the gallbladder: Results of a Japanese Society of Biliary Surgery survey-a multicenter study. J Hepatobiliary Pancreat Surg 16(2): 204-215, 2009. PMID: 19219399:. DOI: 10.1007/s00534-009-0044-3

20 Ito H, Ito K, D'Angelica M, Gonen M, Klimstra D, Allen P, DeMatteo RP, Fong Y, Blumgart LH and Jarnagin WR: Accurate staging for gallbladder cancer: Implications for surgical therapy and pathological assessment. Ann Surg 254(2): 320-325, 2011 PMID: 21617582. DOI: 10.1097/SLA.0b013e31822238d8

21 Endo I, Shimada H, Tanabe M, Fujii Y, Takeda K, Morioka D, Tanaka K, Sekido H and Togo S: Prognostic significance of the number of positive lymph nodes in gallbladder cancer. J Gastrointest Surg 10(7): 999-1007, 2006. PMID: 16843870. DOI: 10.1016/j.gassur.2006.03.006 
22 Wakai T, Shirai Y, Yokoyama N, Nagakura S, Watanabe H and Hatakeyama K: Early gallbladder carcinoma does not warrant radical resection. Br J Surg 88(5): 675-678, 2001. PMID: 11350438. DOI: $10.1046 / \mathrm{j} .1365-2168.2001 .01749 . x$

23 Wakai T, Shirai Y and Hatakeyama K: Radical second resection provides survival benefit for patients with $\mathrm{T} 2$ gallbladder carcinoma first discovered after laparoscopic cholecystectomy. World J Surg 26(7): 867-871, 2002. PMID: 11960212. DOI: 10.1007/ s00268-002-6274-z

24 Ouchi K, Mikuni J and Kakugawa Y: Laparoscopic cholecystectomy for gallbladder carcinoma: Results of a Japanese survey of 498 patients. J Hepatobiliary Pancreat Surg 9(2): 256-260, 2002. PMID: 12140616. DOI: 10.1007/s005340200028

25 Goetze TO and Paolucci V: Immediate re-resection of T1 incidental gallbladder carcinomas: A survival analysis of the German registry. Surg Endosc 22(11): 2462-2465, 2008. PMID: 18247090. DOI: $10.1007 / \mathrm{s} 00464-008-9747-9$

26 Butte JM, Kingham TP, Gönen M, D’Angelica MI, Allen PJ, Fong Y, DeMatteo RP and Jarnagin WR: Residual disease predicts outcomes after definitive resection for incidental gallbladder cancer. J Am Coll Surg 219(3): 416-429, 2014. PMID: 2508794. DOI: 10.1016/j.jamcollsurg.2014.01.069

27 Renshaw AA and Gould EW: Submitting the entire gallbladder in cases of dysplasia is not justified. Am J Clin Pathol 138(3): 374376, 2012. PMID: 22912353. DOI: 10.1309/ajcpb0ztxxif6mof
28 Adsay V, Saka B, Basturk O and Roa JC: Criteria for pathologic sampling of gallbladder specimens. Am J Clin Pathol 140(2): 278280, 2013. PMID: 23897266. DOI: 10.1309/ajcpujpgqiz6dc6a

29 Clemente G, Nuzzo G, De Rose AM, Giovannini I, La Torre G, Ardito F and Giuliante F: Unexpected gallbladder cancer after laparoscopic cholecystectomy for acute cholecystitis: A worrisome picture. J Gastrointest Surg 16(8): 1462-1468, 2012. PMID: 22653330 . DOI: $10.1007 / \mathrm{s} 11605-012-1915-5$

30 Miura F, Okamoto K, Takada T, Strasberg SM, Asbun HJ, Pitt HA, Gomi H, Solomkin JS, Schlossberg D, Han HS, Kim MH, Hwang TL, Chen MF, Huang WS, Kiriyama S, Itoi T, Garden OJ, Liau KH, Horiguchi A, Liu KH, Su CH, Gouma DJ, Belli G, Dervenis C, Jagannath P, Chan ACW, Lau WY, Endo I, Suzuki K, Yoon YS, de Santibañes E, Giménez ME, Jonas E, Singh H, Honda G, Asai K, Mori Y, Wada K, Higuchi R, Watanabe M, Rikiyama T, Sata N, Kano N, Umezawa A, Mukai S, Tokumura H, Hata J, Kozaka K, Iwashita Y, Hibi T, Yokoe M, Kimura T, Kitano S, Inomata M, Hirata K, Sumiyama Y, Inui K and Yamamoto M: Tokyo Guidelines 2018: Initial management of acute biliary infection and flowchart for acute cholangitis. J Hepatobiliary Pancreat Sci 25(1): 31-40, 2018. PMID: 28941329. DOI: 10.1002/jhbp.509

Received December 24, 2020

Revised January 22, 2021

Accepted January 25, 2021 